\title{
A comparison of different 0 -antigen serogroups of Escherichia coli in semen samples of fertile and infertile men
}

\author{
Ali Nabi ${ }^{1,2}$, Mohammad Bagher Khalili ${ }^{3}$, Gilda Eslami ${ }^{4}$, Mahmood Vakili $^{5}$, Fatemeh Anbari ${ }^{2,6}$, Alireza Torki ${ }^{3,7}$ \\ 'Andrology Research Center, Yazd Reproductive Sciences Institute, ${ }^{2}$ Department of Reproductive Biology, Faculty of Medicine, ${ }^{3}$ Department of \\ Microbiology, School of Medicine, ${ }^{4}$ Research Center for Food Hygiene and Safety, ${ }^{5}$ Community Medicine, Monitoring of Health Research Center, School \\ of Medicine, and ${ }^{6}$ Research and Clinical Center for Infertility, Yazd Reproductive Sciences Institute, Shahid Sadoughi University of Medical Sciences, \\ Yazd; ${ }^{7}$ Department of Microbiology, School of Medicine, Iran University of Medical Sciences, Tehran, Iran
}

Objective: Male genital tract infections have been associated with infertility, and Escherichia coli has drawn increasing attention as an important bacterium in this context. This investigation aimed to characterize and compare the distributions of $\mathrm{O}$-antigen serogroups of $E$. coli in the semen samples of fertile and infertile men.

Methods: In this case-control study, semen samples were collected from 618 fertile and 1,535 infertile men. The E. coli-positive samples were evaluated in terms of concentration, morphology, viability, and motility parameters according to the World Health Organization 2010 guidelines. Finally, different serogroups of $E$. coli were identified by multiplex polymerase chain reaction targeting the $\mathrm{O}$-antigen variations of the bacterium.

Results: The prevalence of $E$. coli among fertile men was significantly higher than among infertile men $(p<0.001)$. The sperm morphology, viability, and motility in the $E$. coli-positive fertile group were significantly higher than in the $E$. coli-positive infertile group $(p<0.001)$. E. coli 06 was the most prevalent serogroup found in both groups. However, there was no significant difference in the frequency of different serogroups of $E$. coil between the two groups ( $p=0.55$ ).

Conclusion: Despite the higher prevalence of $E$. coli among fertile men, $E$. coli had more detrimental effects on semen parameters in infertile men. There was no significant difference in $E$. coli serogroups between the fertile and infertile groups.

Keywords: Escherichia coli; Male infertility; Semen; Serogroups

\section{Introduction}

Infertility is a worldwide health problem that causes an emotional impact in about $15 \%$ of cases. On average, male factor infertility is

Received: October 13, 2020 · Revised: May 20, 2021 · Accepted: May 25, 2021 Corresponding author: Alireza Torki

Department of Microbiology, School of Medicine, Shahid Sadoughi University of Medical Sciences, Javan Blvd., Safayeh, Yazd 8916978477, Iran

Tel: +98-91-3250-8432 Fax: +98-91-3250-8432 E-mail: ar.torki@yahoo.com

*This study was financially supported by a grant provided by Shahid Sadoughi University of Medical Sciences.

This is an Open Access article distributed under the terms of the Creative Commons Attribution Non-Commercial License (http://creativecommons.org/licenses/by-nc/4.0/) which permits unrestricted non-commercial use, distribution, and reproduction in any medium, provided the original work is properly cited. responsible for $50 \%$ of reproductive problems [1]. There is considerable variation in the causes of male infertility, including anatomical problems, hormonal disorders, genetic defects, infections, psychological conditions, and lifestyle factors. However, $25 \%-30 \%$ of couples have idiopathic infertility, meaning that the cause of infertility remains unknown $[2,3]$.

Urogenital tract infections (UTIs) are the main cause of infertility in male partners [4]. Studies have reported that UTIs are responsible for $8 \%-35 \%$ of male infertility cases $[5,6]$. Sexually transmitted diseases have negative effects on both spermatogenesis and sperm transfer from the testes to the ejaculation ducts $[7,8]$. In some cases, an infection may create an obstruction in the reproductive tract, thereby causing infertility [9].

Several microorganisms have been isolated from the male repro- 
ductive tract in infertile individuals. Microorganisms can cause infertility by various mechanisms, including sperm agglutination, immobilization of the spermatozoa by direct binding or production of immobilizing factors, interactions with the immune system and induction of chronic inflammation, alteration of the function of accessory sex glands, defects in sperm function, and a decreased proportion of spermatozoa with normal morphology $[10,11]$.

Among bacterial species, Escherichia coli is the most common agent of male reproductive tract infections; therefore, it is the most prevalent microorganism isolated from urine and seminal fluid of patients with reproductive tract disorders. It is hypothesized that the presence of $E$. coli, as is the case for many other bacteria, may decrease sperm concentration, motility, and viability $[12,13]$. Although several studies have investigated the role of $E$. coli in male infertility, some reported there was no association between bacteria and male infertility $[14,15]$. According to a previous study, 174 O-serogroups have been identified for $E$. coli, that some of them are pathogenic [16]. The $01,02,04,06,016,025$, and 075 serogroups were predominantly found in uropathogenic E. coli [17].

No previous studies have compared different serogroups of $E$. coli in semen from infertile and fertile men. For this purpose, this study aimed to investigate the prevalence of $E$. coli and to identify $E$. coli serogroups in the semen of fertile and infertile men. In this study, serogroup identification was based on multiplex polymerase chain reaction (PCR), which is more accurate than serologic detection [16].

\section{Methods}

\section{Study population}

In this case-control study, 618 fertile and 1,535 infertile men with male factor infertility who were referred to the Yazd Infertility Research Center from April 2018 to October 2019 were voluntarily enrolled. All patients were diagnosed as fertile or infertile by a urologist according to the World Health Organization (WHO) 2010 guidelines [17], and then they were screened for the presence of E. coli in their semen. Participants who had used antibiotics within 2 weeks prior to the semen sampling, smokers, varicocelectomy, and samples with mixed infections were excluded. All participants provided written informed consent, the confidentiality of the identity and clinical information of the participants was guaranteed, and the ethical committee of the Research and Clinical Center for Infertility, Yazd, approved the study proposal (IR.IUMS.FMD.REC1396.9323133001).

\section{Sperm analysis}

Semen samples were collected by masturbation into sterile tubes; the abstinence period for all participants was $2-5$ days. Following liquefaction at $37^{\circ} \mathrm{C}$ for 20 minutes, the sperm morphology, concen- tration, viability, and motility parameters (including progressive motility, non-progressive motility and immotility), were evaluated according to the $\mathrm{WHO}$ guidelines for the examination and processing of human semen samples [18].

\section{Isolation of $E$. coli from semen}

To isolate $E$. coli, the semen samples were streaked on plates containing eosin methylene blue using a sterile calibrated loop, and incubated at $37^{\circ} \mathrm{C}$ for $24-48$ hours [19]. The E. coli colonies were phenotypically identified by Gram staining, followed by biochemical tests, including catalase, oxidase, lysine decarboxylase, sulfide-indole-motility, methyl red-Voges-Proskauer, triple sugar iron, and Simmons citrate.

\section{DNA extraction}

A colony of the isolated $E$. coli was grown in $3 \mathrm{~mL}$ of tryptic soy broth at $37^{\circ} \mathrm{C}$ for 24 hours. Then, $1 \mathrm{~mL}$ of the bacterial suspension added into a sterile $1.5 \mathrm{~mL}$ micro-tube, centrifuged at 5,000 $\times g$ for 10 minutes, and washed three times by re-suspending the bacterial pellet in $1 \mathrm{~mL}$ of sterile phosphate-buffered saline and centrifuged at $6,000 \times g$ for 4 minutes. The cells were lysed with $450 \mu \mathrm{L}$ of lysis buffer ( $20 \mathrm{mM}$ Tris, $25 \mathrm{mM}$ EDTA, and $100 \mathrm{mM} \mathrm{NaCl}$ ) and $50 \mu \mathrm{L}$ of sodium dodecyl sulfate (10\%) followed by incubation at $56^{\circ} \mathrm{C}$ for 20 minutes. Then, $300 \mu \mathrm{L}$ of $\mathrm{NaCl}$ was added, mixed, and centrifuged at 12,000 $\times g$ for 10 minutes. The supernatant was equally transferred into two $1.5 \mathrm{~mL}$ micro-tubes, and $1 \mathrm{~mL}$ of cold absolute ethanol was added, mixed, and centrifuged at $12,000 \times g$ for 15 minutes. Cold $70 \%$ ethanol $(300 \mu \mathrm{L})$ was added, mixed, and centrifuged at $12,000 \times g$ for 3 minutes. The supernatant was discarded, and the DNA precipitate was dissolved in $100 \mu \mathrm{L}$ of sterile distilled water at $56^{\circ} \mathrm{C}$ for $10 \mathrm{~min}$ utes and kept at $-20^{\circ} \mathrm{C}$.

\section{Multiplex PCR}

For the molecular characterization of 14 serogroups (categorized as group 1 and group 2) of the isolated E. coli, multiplex PCR was carried out using specific primers (Table 1), as previously described [16]. First, $1 \mu \mathrm{L}$ of each pair of primers $(0.5 \mu \mathrm{L}$ of forward primer and $0.5 \mu \mathrm{L}$ of reverse primer) of group 1 were mixed in a separate micro-tube; the same was done for the primers of group 2. The assay was then performed in a final volume of $20 \mu \mathrm{L}$ consisting of $2 \mu \mathrm{L}$ of template DNA, $10 \mu \mathrm{L}$ of PCR master mix (Taq DNA polymerase 2X Master Mix Red, Ampliqon, Denmark), $7 \mu \mathrm{L}$ of the primer pool (group 1 or group 2 ), and $1 \mu \mathrm{L}$ of diethylpyrocarbonate-treated water ( $\mathrm{ddH} 2 \mathrm{O})$. The thermal profile of the reaction for both groups was one cycle of primary denaturation at $94^{\circ} \mathrm{C}$ for 300 seconds, followed by 40 cycles of denaturation of DNA at $94^{\circ} \mathrm{C}$ for 60 seconds, primer annealing at $58^{\circ} \mathrm{C}$ for 60 seconds, extension at $72^{\circ} \mathrm{C}$ for 90 seconds, and final ex- 
Table 1. Primers used for multiplex PCR assays for 14 serogroups of the Escherichia coli isolated from the semen of fertile and infertile men

\begin{tabular}{|c|c|c|c|c|c|c|}
\hline Serogroup & $\begin{array}{l}\text { Specific } \\
\text { gene }\end{array}$ & $\begin{array}{c}\text { Genebank accession } \\
\text { No. or reference }\end{array}$ & Primer name & Primer sequence $\left(5^{\prime}-3^{\prime}\right)$ & Amplicon size (bp) & $\begin{array}{l}\text { Concentration in } \\
\text { multiplex PCR }(\mu \mathrm{M})\end{array}$ \\
\hline \multicolumn{7}{|l|}{ Group 1} \\
\hline \multirow[t]{2}{*}{ E. coliO1 } & Wzx & GU299791 & wl-14632 & (F) GTGAGCAAAAGTGAAATAAGGAACG & 1,098 & 0.05 \\
\hline & & & wl-14633 & (R) CGCTGATACGAATACCATCCTAC & & \\
\hline \multirow[t]{2}{*}{ E. coliO6 } & Wzy & AJ426423 & wl-14646 & (F) GGATGACGATGTGATTTTGGCTAAC & 783 & 0.07 \\
\hline & & & wl-14647 & (R) TCTGGGTTTGCTGTGTATGAGGC & & \\
\hline \multirow[t]{2}{*}{ E. coliO7 } & Wzx & AF125322 & wl-14648 & (F) CTATCAAAATACCTCTGCTGGAATC & 610 & 0.12 \\
\hline & & & wl-14649 & (R) TGGCTTCGAGATTAAACCTATTCCT & & \\
\hline \multirow[t]{2}{*}{ E. coliO8 } & orf469 & AB010150 & wl-14652 & (F) CCAGAGGCATAATCAGAAATAACAG & 448 & 0.12 \\
\hline & & & wl-14653 & (R) GCAGAGTTAGTCAACAAAAGGTCAG & & \\
\hline \multirow[t]{2}{*}{ E. coliO16 } & Wzx & AAC31631 & wl-14654 & (F) GGTTTCAATCTCACAGCAACTCAG & 302 & 0.13 \\
\hline & & & wl-14655 & (R) GTTAGAGGGATAATAGCCAAGCGG & & \\
\hline \multirow[t]{2}{*}{ E. coliO21 } & Wzx & EU694098 & wl-14676 & (F) CTGCTGATGTCGCTATTATTGCTG & 209 & 0.12 \\
\hline & & & wl-14677 & (R) TGAAAAAAAGGGAAACAGAAGAGCC & & \\
\hline \multirow[t]{2}{*}{ E. coliO75 } & Wzy & GU299795 & wl-17413 & (F) GAGATATACATGGGGAGGTAGGCT & 511 & 0.07 \\
\hline & & & wl-17414 & (R) ACCCGATAATCATATTCTTCCCAAC & & \\
\hline \multicolumn{7}{|l|}{ Group 2} \\
\hline \multirow[t]{2}{*}{ E. coliO2 } & Wzy & GU299792 & wl-14636 & (F) AGTGAGTTACTTTTTAGCGATGGAC & 770 & 0.07 \\
\hline & & & wl-14637 & (R) AGTTTAGTATGCCCCTGACTTTGAA & & \\
\hline \multirow[t]{2}{*}{ E. coliO4 } & Wzx & AY568960 & wl-14642 & (F) TTGTTGCGATAATGTGCATGTTCC & 664 & 0.07 \\
\hline & & & wl-14643 & (R) AATAATTTGCTATACCCACACCCTC & & \\
\hline \multirow[t]{2}{*}{ E. coliO15 } & Wzy & AY647261 & wl-14672 & (F) TCTTGTTAGAGTCATTGGTGTATCG & 183 & 0.08 \\
\hline & & & wl-14673 & (R) ATAAAACGAGCAAGCACCACACC & & \\
\hline \multirow[t]{2}{*}{ E. coliO18 } & Wzx & GU299793 & wl-14656 & (F) GTTCGGTGGTTGGATTACAGTTAG & 551 & 0.08 \\
\hline & & & wl-14657 & (R) CTACTATCATCCTCACTGACCACG & & \\
\hline \multirow[t]{2}{*}{ E. coliO22 } & Wzx & DQ851855 & wl-14660 & (F) TTCATTGTCGCCACTACTTTCCG & 468 & 0.08 \\
\hline & & & wl-14661 & (R) GAAACAGCCCATGACATTACTACG & & \\
\hline \multirow[t]{2}{*}{ E. coliO25 } & Wzy & GU299796 & wl-14666 & (F) AGAGATCCGTCTTTTATTTGTTCGC & 230 & 0.08 \\
\hline & & & wl-14667 & (R) GTTCTGGATACCTAACGCAATACCC & & \\
\hline \multirow[t]{2}{*}{ E. coliO83 } & Wzx & GU299797 & wl-14668 & (F) GTACACCAGGCAAACCTCGAAAG & 362 & 0.08 \\
\hline & & & wl-14669 & (R) TTCTGTAAGCTAATGAATAGGCACC & & \\
\hline
\end{tabular}

The serogroups were divided into two groups according to a previous study [18].

$P C R$, polymerase chain reaction; $F$, forward; $R$, reverse.

tension at $72^{\circ} \mathrm{C}$ for 300 seconds. The PCR products were detected by electrophoresis on 1\% agarose gel containing DNA Green Viewer (P7890; ParsTous Biotechnology, Mashhad, Iran), using a 50 kbp DNA ladder (PR901633; Fermentas, Stanford, CA, USA) and under an ultraviolet Benchtop transilluminator (LTF00205; Bodensee, Baden-Württemberg, Germany). The amplified products were sequenced for final confirmation.

\section{Statistical analysis}

For the statistical analysis, the two-sample proportional test, Mann-Whitney $U$-test, and Student $t$-test were performed using IBM SPSS ver. 20 (IBM Corp., Armonk, NY, USA). The Student $t$-test (independent sample $t$-test) was used to compare sperm parameters between the fertile and infertile groups. The normality of the data dis- tribution was checked using the Kolmogorov-Smirnov test. A $p$-value $<0.05$ was considered to indicate statistical significance.

\section{Results}

The two groups were matched for demographic characteristics. The mean ages of the E. coli-positive fertile (ECPF) and E. coli-positive infertile (ECPI) groups were $31.0 \pm 2.8$ and $33.8 \pm 6.2$ years, respectively. E. coli was isolated at a significantly higher frequency in the semen of fertile men than in that of infertile men ( $p<0.001) ; 80$ out of the 618 fertile patients (12.9\%) had E. coli in their semen, comprising the ECPF group, while 80 out of the 1,535 infertile men (5.2\%) had E. coli in their semen, comprising the ECPI group. The sperm parameters of the ECPF and ECPI groups are compared in Ta- 
Table 2. Comparisons of the sperm parameters between the ECPF and ECPI groups

\begin{tabular}{|c|c|c|c|}
\hline Variable & $\operatorname{ECPF}(n=575)$ & $\operatorname{ECPI}(n=1,725)$ & $p$-value \\
\hline Concentration $\left(\times 10^{6} / \mathrm{mL}\right)$ & $106.2 \pm 53.2$ & $98.8 \pm 51.7$ & 0.58 \\
\hline Normal morphology (\%) & $7.3 \pm 3.4$ & $2.4 \pm 2.5$ & $<0.001^{\text {a) }}$ \\
\hline Progressive motility (\%) & $61.3 \pm 9.4$ & $20.6 \pm 5.3$ & $<0.001^{\mathrm{a})}$ \\
\hline Non-progressive motility (\%) & $10.1 \pm 5.7$ & $9.2 \pm 7.1$ & $<0.001^{\text {a) }}$ \\
\hline Immotile (\%) & $28.6 \pm 7.6$ & $70.2 \pm 9.3$ & $<0.001^{a)}$ \\
\hline Viability & $42.6 \pm 6.3$ & $15.4 \pm 3.5$ & $<0.001^{\mathrm{a})}$ \\
\hline
\end{tabular}

Values are presented as mean \pm standard deviation.

$\mathrm{ECPF}$, Escherichia coli-positive fertile; ECPI, E. coli-positive infertile.

${ }^{\text {a) }} \mathrm{p}$-value $\leq 0.05$ was considered to indicate a statistically significant difference between the ECPF and ECPI groups.

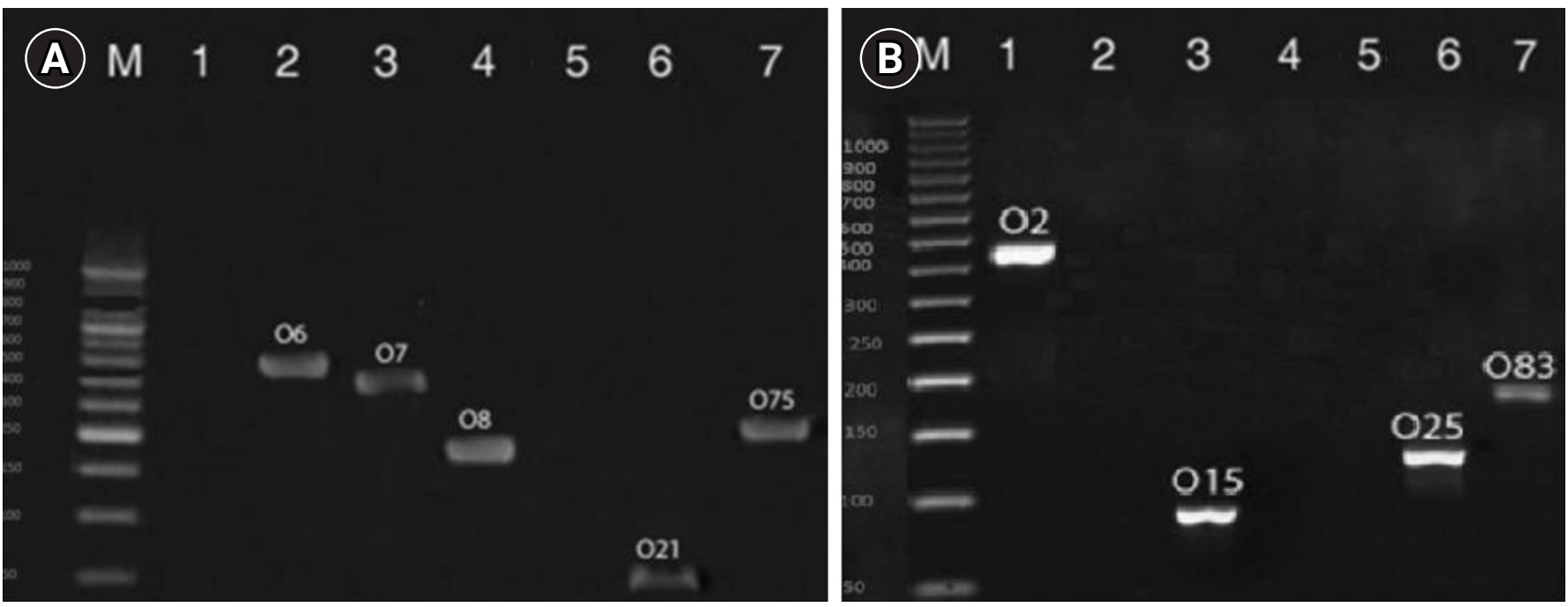

Figure 1. Results of multiplex polymerase chain reaction (PCR) divided into group 1 (A) and group 2 (B) for identification and comparison of serogroup distributions of Escherichia coli in the semen of the E. coli-positive fertile and E. coli-positive infertile groups.

ble 2. The frequencies of normal morphology, motility, and viability of the sperm in the ECPF group were significantly higher than those in the ECPI group $(p<0.001)$. There was no significant difference in sperm concentration between the two groups.

Multiplex PCR was carried out in order to identify and compare the serogroup distributions of the $E$. coli isolated from the ECPF and ECPI groups (Figure 1). As shown in Table 3, the 02, 06, 07, 08, 015, 021, $\mathrm{O} 25,075$, and 083 serogroups were detected in the ECPF group, and the $02,06,07,08,015,025$, and 075 serogroups were found in the ECPI group. 06 was the most prevalent serogroup found in both the ECPF (44.8\%) and ECPI (50\%) groups. The 08, 025, and 075 serogroups were the second most prevalent serogroups in the ECPF group, while 025 and 075 were the second most prevalent serogroups in the ECPI group (Table 3). However, there was no significant difference in the frequencies of different serogroups of $E$. coil between the ECPF and ECPI groups ( $p>0.05$ ).

\section{Discussion}

It has been accepted that reproductive bacterial infections are associated with male infertility [20]. Some studies have suggested that bacterial infections can induce inflammation or create changes in the biological or physiological function of the male reproductive system [21-23]. Filipiak et al. [24] found no statistically significant relationship between the presence of $E$. coli in semen and reduced sperm motility and morphology in infertile men. In contrast, Puerta Suarez et al. [25] reported that $E$. coli could significantly decrease sperm motility. However, the putative detrimental effect of $E$. coli on the seminal fluid and male infertility remains controversial $[26,27]$. In the present study, we evaluated the prevalence of $E$. coli isolated from semen samples of fertile and infertile men. To the best of our knowledge, this was the first study to compare the prevalence of different serogroups of $E$. coli in the semen of infertile and fertile men using multiplex PCR, which can detect serogroups of $E$. coli with high specificity and sensitivity. The principal limitation of this technique is 
Table 3. Comparisons between the serogroups of the ECPF and ECPI groups

\begin{tabular}{lccc}
\hline Serogroups & ECPF & ECPI & $p$-value \\
\hline 01 & 0 & 0 & - \\
02 & $2(3)$ & $4(6.25)$ & 0.37 \\
04 & 0 & 0 & - \\
06 & $30(44.8)$ & $32(50)$ & 0.55 \\
07 & $5(7.5)$ & $4(6.25)$ & 0.78 \\
08 & $8(11.9)$ & $4(6.25)$ & 0.26 \\
015 & $4(6)$ & $4(6.25)$ & 0.95 \\
016 & 0 & 0 & - \\
018 & 0 & 0 & - \\
021 & $1(1.5)$ & 0 & 0.33 \\
022 & 0 & 0 & - \\
025 & $8(11.9)$ & $8(12.5)$ & 0.92 \\
075 & $8(11.9)$ & $8(12.5)$ & 0.92 \\
083 & $1(1.5)$ & 0 & 0.33 \\
Total & $67(100)$ & $64(100))$ & - \\
\hline
\end{tabular}

Values are presented as number (\%). A $p$-value $\leq 0.05$ was considered to indicate a statistically significant difference between the ECPF and ECPI groups; using this criterion, there was no significant difference in the serogroups of Escherichia coli between the two groups. The statistical analysis was conducted using the Mann-Whitney test.

ECPF, Escherichia coli-positive fertile; ECPI, E. coli-positive infertile.

that some samples were non-typeable, meaning that we could not detect the serotype with our primers. Furthermore, collecting this number of samples to analyze using multiplex PCR required a considerable investment of time and money.

Our results showed that the prevalence of $E$. coli in the semen of fertile men was significantly higher than in that of infertile men. Although the prevalence of $E$. coli was low in infertile men, the detrimental effect of $E$. coli on semen quality was more severe in this group. This finding is similar to previous clinical evidence showing that bacteria isolated from the genital tracts of normozoospermic men had no effect on semen quality; however, in infertile men, an impairment of sperm parameters was seen due to the diminished antioxidant capacity of sperm [28]. However, in line with our study, previous findings have confirmed that bacterial contamination of the semen samples of fertile men did not compromise the sperm quality, while in infertile men, it is possible that bacteria further deteriorated the overall quality of the seminal plasma [29]. Salisu et al. [30] reported that E. coli constituted one of the main microorganisms in the semen samples of infertile men, and also they concluded that high levels of $E$. coli had negative effects on sperm parameters, including sperm count, motility, and morphology.

Our results showed that sperm parameters such as motility, morphology, and viability were significantly impaired in infertile patients who tested positive for $E$. coli in comparison with the semen samples from healthy fertile men that tested positive for $E$. coli. Because both groups tested positive for $E$. coli, it can be inferred that E. coli may have a greater impact on infertile men due to etiology of male infertility. It has been suggested that $E$. coli can decrease male fertility potential by several mechanisms, including reduction of sperm parameters [31], defects in spermatogenesis, and reduction of the secretory capacity in the male accessory glands [32].

Infections of the accessory glands and male reproductive tract are harmful for sperm maturation. Epididymitis is a common urogenital disease in men between 18 and 50 years (the optimal age for fertility) [33]. Interestingly, E. coli has been found to be the most common cause of epididymitis and prostatitis [34]. Lang et al. [35] reported that alterations in spermatogenesis and defects in sperm structure occurred in almost $60 \%$ of patients with acute epididymitis.

The mechanism of the effect of $E$. coli on male fertility remains unknown, but it has been generally accepted that $E$. coli is the most common bacterium causing genital tract infections [36]. Fraczek et al. [37] reported that in vitro contact of $E$. coli with ejaculated spermatozoa can severely damage sperm membrane stability and mitochondrial activity. Defects in sperm membrane and activity were responsible for reducing male fertility potential. Another study evaluated the mechanism of the effects of $E$. coli on sperm and suggested that several soluble factors and adhesion molecules secreted by $E$. coli may be responsible for defects in sperm function, causing infertility in men [22].

It is noteworthy that microorganisms affect male infertility through various mechanisms, depending on the host immune system, age, sexual activity, and genetic background. Studies have reported that some microorganisms, including Streptococcus viridans, E. coli, Enterococcus faecalis, and Staphylococcus aureus together or alone, were harmful to male fertility potential $[38,39]$. In the present study, we only focused on E. coli as the most important bacterium in semen; other microorganisms were not evaluated.

Additionally, in the present study, molecular O-serogrouping of the $E$. coli isolates revealed slight differences in the serotype distribution between fertile and infertile men; however, these differences were not statistically significant between the two groups. E. coli $\mathrm{O6}$ was the most common isolate in semen samples of both fertile and infertile men. This finding was similar to that of Lloyd et al. [40], who found the 06 serogroup in the semen samples. Furthermore, Boguen et al. [12] reported that the 01,02 , and 04 serogroups were the most prevalent serogroups of $E$. coli in the semen. Boguen et al. [41] reported that serogroups affected neither sperm viability nor mitochondrial membrane potential in infertile men. In that study, the $\mathrm{O} 4$ strain decreased sperm motility; however, we did not detect the 01 and 04 serogroups in the semen of either fertile or infertile men.

Based on the findings of this study, despite the higher prevalence 
of $E$. coli in the semen of fertile men than in that of infertile men, the distribution of $E$. coli subgroups did not show any significant difference between the two study groups. In this study, $\mathrm{O6}$ was the most common serogroup of $E$. coli in both groups. In addition, it seems that $E$. coli may be responsible for changes in sperm parameters including motility, morphology, and viability. More studies are suggested to clarify this issue in the future.

\section{Conflict of interest}

No potential conflict of interest relevant to this article was reported.

\section{Acknowledgments}

The authors would like to express their gratitude to all participants of this study.

\section{Author contributions}

Conceptualization: AN, MBK. Funding acquisition: AN, AT. Methodology: GE, AT, MV. Project administration: AN, AT. Writing-original draft: all authors. Writing-review \& editing: FA.

\section{References}

1. Panner Selvam MK, Agarwal A, Pushparaj PN, Baskaran S, Bendou H. Sperm proteome analysis and identification of fertility-associated biomarkers in unexplained male infertility. Genes (Basel) 2019;10:522.

2. Gassei K, Orwig KE. Experimental methods to preserve male fertility and treat male factor infertility. Fertil Steril 2016;105:256-66.

3. Kumar N, Singh AK. Trends of male factor infertility, an important cause of infertility: a review of literature. J Hum Reprod Sci 2015;8:191-6.

4. Solomon M, Henkel R. Semen culture and the assessment of genitourinary tract infections. Indian J Urol 2017;33:188-93.

5. Abdel-Naser MB, Altenburg A, Zouboulis CC, Wollina U. Schistosomiasis (bilharziasis) and male infertility. Andrologia 2019;51: e13165.

6. lovene MR, Martora F, Bombace F, Montella F, Del Vecchio C, De Rosa $M$, et al. A new enrichment diagnostic platform for semen culture. J Microbiol Methods 2018;144:168-72.

7. Abdel-Naser MB, Wollina U, Lohan M, Zouboulis CC, Altenburg A. Schistosomiasis (Bilharziasis) ova: an incidental finding in testicular tissue of an obstructive azoospermic man. Andrologia 2018; 50:e13131.
8. Zeyad A, Hamad MF, Hammadeh ME. The effects of bacterial infection on human sperm nuclear protamine P1/P2 ratio and DNA integrity. Andrologia 2018;50:e12841.

9. Chen XF, Chen B, Liu W, Huang YP, Wang HX, Huang YR, et al. Microsurgical vasoepididymostomy for patients with infectious obstructive azoospermia: cause, outcome, and associated factors. Asian J Androl 2016;18:759-62.

10. Stojanov M, Baud D, Greub G, Vulliemoz N. Male infertility: the intracellular bacterial hypothesis. New Microbes New Infect 2018; 26:37-41.

11. Gimenes F, Souza RP, Bento JC, Teixeira JJ, Maria-Engler SS, Bonini MG, et al. Male infertility: a public health issue caused by sexually transmitted pathogens. Nat Rev Urol 2014;11:672-87.

12. Boguen R, Treulen F, Uribe P, Villegas JV. Ability of Escherichia coli to produce hemolysis leads to a greater pathogenic effect on human sperm. Fertil Steril 2015;103:1155-61.

13. Motrich RD, Salazar FC, Breser ML, Mackern-Oberti JP, Godoy GJ,

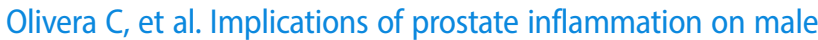
fertility. Andrologia 2018;50:e13093.

14. Kaur K, Prabha V. Spermagglutinating Escherichia coli and its role in infertility: in vivo study. Microb Pathog 2014;69-70:33-8.

15. Jue JS, Ramasamy R. Significance of positive semen culture in relation to male infertility and the assisted reproductive technology process. Transl Androl Urol 2017;6:916-22.

16. Li D, Liu B, Chen M, Guo D, Guo X, Liu F, et al. A multiplex PCR method to detect 14 Escherichia coli serogroups associated with urinary tract infections. J Microbiol Methods 2010;82:71-7.

17. Terai A, Yamamoto S, Mitsumori K, Okada Y, Kurazono H, Takeda Y, et al. Escherichia coli virulence factors and serotypes in acute bacterial prostatitis. Int J Urol 1997;4:289-94.

18. World Health Organization. WHO laboratory manual for the examination and processing of human semen. Geneva: World Health Organization; 2010.

19. Nabi A, Khalili MA, Halvaei I, Ghasemzadeh J, Zare E. Seminal bacterial contaminations: probable factor in unexplained recurrent pregnancy loss. Iran J Reprod Med 2013;11:925-32.

20. Weidner W, Pilatz A, Diemer T, Schuppe HC, Rusz A, Wagenlehner F. Male urogenital infections: impact of infection and inflammation on ejaculate parameters. World J Urol 2013;31:717-23.

21. Schuppe HC, Pilatz A, Hossain H, Diemer T, Wagenlehner F, Weidner W. Urogenital infection as a risk factor for male infertility. Dtsch Arztebl Int 2017;114:339-46.

22. Fraczek M, Kurpisz M. Mechanisms of the harmful effects of bacterial semen infection on ejaculated human spermatozoa: potential inflammatory markers in semen. Folia Histochem Cytobiol 2015; 53:201-17.

23. Schagdarsurengin U, Western P, Steger K, Meinhardt A. Develop- 
mental origins of male subfertility: role of infection, inflammation, and environmental factors. Semin Immunopathol 2016;38:76581.

24. Filipiak E, Marchlewska K, Oszukowska E, Walczak-Jedrzejowska R, Swierczynska-Cieplucha A, Kula K, et al. Presence of aerobic micro-organisms and their influence on basic semen parameters in infertile men. Andrologia 2015;47:826-31.

25. Puerta Suarez J, Sanchez LR, Salazar FC, Saka HA, Molina R, Tissera $A$, et al. Chlamydia trachomatis neither exerts deleterious effects on spermatozoa nor impairs male fertility. Sci Rep 2017;7:1126.

26. Biswas B, Bhushan S, Rajesh A, Suraj SK, Lu Y, Meinhardt A, et al. Uropathogenic Escherichia coli (UPEC) induced antimicrobial gene expression in the male reproductive tract of rat: evaluation of the potential of Defensin 21 to limit infection. Andrology 2015; 3:368-75.

27. Mashaly M, Masallat DT, Elkholy AA, Abdel-Hamid IA, Mostafa T. Seminal Corynebacterium strains in infertile men with and without leucocytospermia. Andrologia 2016;48:355-9.

28. Sanocka-Maciejewska D, Ciupinska M, Kurpisz M. Bacterial infection and semen quality. J Reprod Immunol 2005;67:51-6.

29. Moretti E, Capitani S, Figura N, Pammolli A, Federico MG, Giannerini $\mathrm{V}$, et al. The presence of bacteria species in semen and sperm quality. J Assist Reprod Genet 2009;26:47-56.

30. Salisu N, Agbo EB, Yahaya S, Muhammad A. Assessment of microbiological quality of male patients with infertility at Murtala Muhammad specialist hospital Kano, Nigeria. MOJ Bioequiv Availab 2018;5:170-4.

31. Prabha V, Sandhu R, Kaur S, Kaur K, Sarwal A, Mavuduru RS, et al. Mechanism of sperm immobilization by Escherichia coli. Adv Urol 2010;2010:240268.

32. Pilatz A, Ceylan I, Schuppe HC, Ludwig M, Fijak M, Chakraborty T, et al. Experimental Escherichia coli epididymitis in rats: assessment of testicular involvement in a long-term follow-up. Andro- logia 2015;47:160-7.

33. Grabe M, Bartoletti TE, Johansen B, Cai T, Cek M, Koves B, et al. Guidelines on urological infections. Arnhem: European Association of Urology; 2015.

34. Bhushan S, Hossain H, Lu Y, Geisler A, Tchatalbachev S, Mikulski Z, et al. Uropathogenic E. coli induce different immune response in testicular and peritoneal macrophages: implications for testicular immune privilege. PLoS One 2011;6:e28452.

35. Lang T, Dechant M, Sanchez V, Wistuba J, Boiani M, Pilatz A, et al. Structural and functional integrity of spermatozoa is compromised as a consequence of acute uropathogenic E. coli-associated epididymitis. Biol Reprod 2013;89:59.

36. Cools P. The role of Escherichia coli in reproductive health: state of the art. Res Microbiol 2017;168:892-901.

37. Fraczek M, Piasecka M, Gaczarzewicz D, Szumala-Kakol A, Kazienko A, Lenart S, et al. Membrane stability and mitochondrial activity of human-ejaculated spermatozoa during in vitro experimental infection with Escherichia coli, Staphylococcus haemolyticus and Bacteroides ureolyticus. Andrologia 2012;44:315-29.

38. Fraczek M, Hryhorowicz M, Gill K, Zarzycka M, Gaczarzewicz D, Jedrzejczak P, et al. The effect of bacteriospermia and leukocytospermia on conventional and nonconventional semen parameters in healthy young normozoospermic males. J Reprod Immunol 2016;118:18-27.

39. La Vignera S, Vicari E, Condorelli RA, D'Agata R, Calogero AE. Male accessory gland infection and sperm parameters (review). Int J Androl 2011;34(5 Pt 2):e330-47.

40. Lloyd AL, Rasko DA, Mobley HL. Defining genomic islands and uropathogen-specific genes in uropathogenic Escherichia coli. J Bacteriol 2007;189:3532-46.

41. Boguen R, Uribe P, Treulen F, Villegas JV. Distinct isolates of uropathogenic Escherichia coli differentially affect human sperm parameters in vitro. Andrologia 2014;46:943-7. 